\title{
Correction to: An enigma: how can freshwater eels (Anguilla spp.) be such a successful genus yet be universally threatened?
}

\author{
Donald J. Jellyman $\mathbb{D}$
}

Published online: 19 July 2021

(C) Springer Nature Switzerland AG 2021

\section{Correction to: Rev Fish Biol Fisheries https://doi.org/10.1007/s11160-021- 09658-8}

The author mistakenly included species listed as "Near Threatened" on the IUCN Red List of Threatened Species within the "Threatened" category. The "Threatened' Categories" are in fact "Vulnerable", "Endangered" and "Critically Endangered".

As a result, the second sentence of the abstract section should read: "Of the 19 recognised species or subspecies, 4 temperate species and 2 tropical species are listed within IUCN Threatened Species categories".

Also, the third paragraph of the section "Importance and status of species" should read: "Overall, the genus is in a parlous state. Of the recognised 19 species and sub-species, 4 of the tropical species are listed by IUCN (2017) as Data Deficient so cannot be assessed but 2 of the remaining 9 tropical species are within Threatened Species categories (Near Threatened, Vulnerable, Endangered, Critically Endangered), while 4 temperate species are within this Threatened Species classification (Table 1). The three species most important to world economy, are either critically endangered (A. anguilla) or endangered $(A$. rostrata, A. japonica)."

The author is thankful to the IUCN Anguillid Eel Specialist Group for pointing out this error. However, this correction does not change the overall hypothesis presented in the article i.e. that surplus production of juvenile eels drives continental populations via such mechanisms as density dependent upstream migrations, and substantial reductions in recruitment have uncoupled such processes.

Publisher's Note Springer Nature remains neutral with regard to jurisdictional claims in published maps and institutional affiliations.
The original article can be found online at https:// doi.org/10.1007/s11160-021-09658-8.

D. J. Jellyman $(\square)$

NIWA, PO Box 8602, Riccarton, Christchurch 8440, New

Zealand

e-mail: don.jellyman@niwa.co.nz 